\title{
QUALITY OF LIFE, WORK ABILITY AND OTHER IMPORTANT INDICATORS OF WOMEN'S OCCUPATIONAL HEALTH
}

NEGAH TAVAKOLI-FARD ${ }^{1}$, SEYED-ALIREZA MORTAZAVI ${ }^{2}$, JALIL KUHPAYEHZADEH ${ }^{1}$, and MARZIEH NOJOMI ${ }^{1}$

Iran University of Medical Sciences, Tehran, Iran

${ }^{1}$ Department of Community Medicine

${ }^{2}$ Department of Occupational Medicine

\begin{abstract}
Objectives: Work ability may be considered as an important aspect of well-being and health status. One of the most important factors in association with work ability is health-related quality of life (HRQoL). The aim of this study has been to determine the association between work ability, individual characteristics and HRQoL of female workers. Material and Methods: The design of this study has been cross-sectional. The work ability index (WAI) and Short-Form General Health Survey (SF-12) questionnaires were used to collect data. Three hundred and twenty female workers were selected from food supplier factories in Karaj. One-way analysis of variance, Pearson's correlation analysis, independent sample t-test and multiple linear regression methods were used to analyze data. Results: Mean (M) and standard deviation (SD) of the WAI stood at 35.02 and 5.57, respectively. The categories of the WAI for women being as follows: $8.8 \%$ poor, $62 \%$ moderate, $25.4 \%$ good and $3.7 \%$ excellent. Mean \pm SD for the physical component summary (PCS) and mental component summary (MCS) of quality of life was $58.84 \pm 11.12$ and $57.45 \pm 9.94$, respectively. There was a positive significant association between the PCS and MCS with the WAI $(p=0.0001)$. Workers with higher education had a better work ability $(p=0.002)$ and shift-work workers had a worse work ability $(\mathrm{p}=0.03)$. Conclusions: Work ability of majority of women was moderate. Considering mean age of studied women (27.6 years old), this work ability is not satisfactory. Physical and mental components of the HRQoL were the important factors associated with work ability.
\end{abstract}

Key words:

Women workers, Work ability index, Quality of life, Job satisfaction, Women's health, Mental health

\section{INTRODUCTION}

Around the world, women are at a hardship position as compared to men in various domains of community life. Women's work is no exception. Women's working conditions are less often researched, and their associated health problems less often diagnosed and compensated for than in the case of men [1,2]. Women make up $40 \%$ of the paid workforce around the world [3]. In addition, it has been shown that women on average continue to earn less than men, even for the same occupation [4].

A major research line in women's job health accounts for musculoskeletal problems [5]. Working conditions for women such as repetitive work, prolonged standing, and carrying heavy loads could be a source of some musculoskeletal conditions in the case of female workers.

Source of financial support: Iran University of Medical Sciences, No. 19891. Grant manager: Marzieh Nojomi, MD, MPH.

Received: May 17, 2014. Accepted: March 4, 2015.

Corresponding author: M. Nojomi, Iran University of Medical Sciences, Department of Community Medicine, School of Medicine, Crossroads of Hemmat and Chamran Expressways, 15875-6171 Tehran, Iran (e-mail: mnojomi@iums.ac.ir). 
Stress as an important job health problem was identified in female workers too. Stress may be related to hypertension, headaches, and psychological distress in female workers. Women and men have also different psychological health risks in paid employment. A study of over 10000 employees in 6 French businesses between 2000 and 2007 showed that, partly due to differences in working conditions, women were almost twice as likely to report stress as men [6]. Also, there are some studies which showed a link between psychological stress, anxiety and depression about women's workplace conditions $[7,8]$.

It has been shown that stressful working conditions have an association with both mental and physical diseases in the case of women [9]. Quality of life (QoL) is one of the most important aspects of mental health. Quality of life is a sense of well-being and has an important effect on human lives. Quality of life is defined by the World Health Organization (WHO) as "an individual's perception of his or her position in life in the context of the culture and value systems, in which one lives, and in relation to goals, expectations, standards and concerns" [10]. Assessing QoL could be a clue for identifying the metal health because it includes physical, mental, and social aspects of life.

Ability of a worker to do his/her job, considering the specific work demands, individual health status, mental resources and work life have been defined as work ability [11]. It has been shown that work ability is associated with all domains of health-related quality of life (HRQoL) and there is a close association between the perceived work ability and the HRQoL too [12]. It also has been shown that satisfactory work ability is associated with a better HRQoL [13]. Therefore, it is suggested that the promotion of work ability may have important effects on the HRQoL. It seems that improving work ability is one of the most important ways to increase ability and to prevent early retirement in workers. The work ability index (WAI) is a measure designed for job health services and is used today in clinical practice as well as for research purposes worldwide to assess work ability [14].
According to the last census in Iran, women make up more than $11 \%$ of the work force and $5.3 \%$ of industrial workers in Iran. Although there has been more and more research on female workers' experiences in recent years, there is a need for additional research on the risks and health problems affecting female workers within and across jobs, and for more gender sensitive job health research in general. Today, one of the most important aspects of human resources management is to determine factors that promote work ability.

The aim of this study has been to determine the association between the HRQoL, work ability, and individual characteristics of female workers of food supplier factories in Karaj, Iran.

\section{MATERIAL AND METHODS \\ Study setting and sample}

Using a cross-sectional study, data was collected from October 2012 till August 2013. Karaj city, Iran was the setting of data collection. Karaj is a city with the population of 1967005 located $49 \mathrm{~km}$ away from Tehran. All female workers who are working in food supplier factories in the county around Karaj city were the sampled population (about 1200 workers). The questionnaires were offered to 400 selected female workers using the non-probability sampling method. Finally, 328 complete questionnaires were assessed (response rate 80\%). The inclusion criteria included: working in food supplier factories and having desire to participate in the survey. All women signed an informed consent to participate in the study. The objectives of the study were explained to them. The study was approved by research technology affairs of Tehran University of Medical Sciences.

\section{Measurement and tools}

Data was collected using 2 questionnaires, the Persian version of the WAI, and the Short-Form General Health Survey (SF-12). 
Work ability was measured by means of the WAI self-assessment questionnaire. This questionnaire was developed by the Finnish Institute of Occupational Health (FIOH). This measure has 7 sections, including current work ability compared with the lifetime best (0-10 points), work ability in relation to the demands of the job (210 points), the number of current diseases diagnosed by a physician (1-7 points), estimated work impairment due to diseases (1-6 points), sick leave during the past year (1-5 points), personal prognosis of work ability after 2 years (1, 4 or 7 points) and mental resources, referring to the workers' life in general, both at work and during leisure time (1-4 points). The score of the WAI ranged 7-49 points and it was categorized into 4 levels: poor (7-27 points), moderate (28-36 points), good (3743 points) and excellent (44-49 points) [15]. The reliability and validity of the Persian version of the WAI was reported to be satisfactory [16].

Quality of life was assessed by means of the SF-12. The SF-12 was developed as a shorter alternative to the SF-36 applicable to large-scale health surveys where application of the longer instrument would be too timeconsuming or costly. The SF-12 has 12 questions which are grouped into 8 domains or scales of physical functioning (PF), role limitations due to physical health (RP), bodily pain (BP), general health perception $(\mathrm{GH})$, social functioning (SF), role limitations due to emotional problems (RE), vitality (VT), and mental health (MH). These 8 scales could be reduced into 2 summary components of the physical component summary (PCS) and mental component summary (MCS). The SF-12 was adapted and validated to Persian conditions by Rohani et al. [17]. The final score of the SF-12 ranged 0-100; a higher score, indicating a better HRQoL. The mean (M) and standard deviation (SD) of both the physical and mental component summaries presented in this study are related to $\mathrm{M}=50$ and $\mathrm{SD}=10$ in the American population. The mental health summary score ranged 8-74, whereas the physical health summary score ranged 4-73. These factors were based on the median (Me), divided into 2 groups of high and low HRQoL [18].

In addition to the mentioned measures, socio-demographic characteristics were also measured and addressed as potential confounders in the multivariate analysis. These variables were age, marital status, education, income, work experience and shift of work.

\section{Statistical analysis}

Statistical analysis was performed using SPSS software package (version 20, SPSS Inc, Chicago, IL). Descriptive index (mean, standard deviation, median and relative frequency) were used to summarize the characteristics of women. Distribution of numeric variables was assessed by means of the Smirnov-Kolmogorov test. According to the type of distribution, an appropriate parametric or equivalent nonparametric tests were used. Quantitative variables without normal distribution were summarized as median. Mean and SD were used to describe the WAI score due to having normal distribution. The association between quantitative variables and the work ability index was tested using Pearson's correlation coefficient. The association between demographics variables, PCS and MCS with the WAI was evaluated using the multiple linear regression analysis. Work ability index was considered as a dependent variable in the model. Significant level was set as 0.05 .

\section{RESULTS}

\section{Demographic characteristics}

Demographic characteristics are shown in the Table 1. Mean \pm SD age of the workers was 27.6 \pm 5.7 years old. The median duration of work and salary were 36 months and 5000000 Rials (the Iranian currency, and officially 29000 Rials = 1 US dollar), respectively. About $70 \%$ of workers were single and $29 \%$ were married. Seventeen percent of workers were shift-work workers and $83 \%$ non-shift work workers. 
Table 1. Characteristics of female workers of food industrial in Karaj, 2012-2013

\begin{tabular}{lc}
\hline \multicolumn{1}{c}{ Variable } & $\begin{array}{c}\text { Workers } \\
(\mathrm{N}=328)\end{array}$ \\
\hline Age [years] & \\
$\mathrm{M} \pm \mathrm{SD}$ & $27.65 \pm 5.72$ \\
min.-max & $18-59$ \\
Marital status [n (\%)] & \\
$\quad$ married & $94(28.9)$ \\
single & $234(70.1)$ \\
Education [n (\%)] & \\
high school graduated & $230(70.12)$ \\
$\quad$ university education & $98(29.87)$ \\
Work experience [months] (Me) & 36 \\
Income [Rials/month] (Me) & 5000000 \\
Shift of work [n (\%)] & \\
shift work & $270(16.7)$ \\
non-shift work & $54(83.3)$ \\
\hline
\end{tabular}

$\mathrm{M}$ - mean; SD - standard deviation; min. - minimal value; $\max$ - maximal value; $\mathrm{Me}$ - median.

\section{Work ability index and health-related quality of life}

The $\mathrm{M} \pm \mathrm{SD}$ of the WAI were $35.02 \pm 5.57$. According to the WAI classification, most of the participants had a good $(25.4 \%)$ or moderate $(62.1 \%)$ work ability. The proportions of excellent and poor work ability were $3.7 \%$ and $8.8 \%$, respectively. The minimum and maximum score of the WAI was 23 and 47, respectively. The scores of different levels of the WAI were: $8.3(0-10)$ in capacity for work, 3.91 (0-10) in physical and mental demands, 4.92 $(0-7)$ in diagnosed diseases, $4.46(0-6)$ in incapacity for work, $3.32(0-5)$ in absenteeism, $4.98(0-7)$ in own prognosis and $6.45(0-12)$ in mental resources. The $\mathrm{M} \pm \mathrm{SD}$ of PCS and MCS were 58.84 \pm 11.12 and 57.45 \pm 9.94 , respectively. The minimum and maximum scores for PCS were 23.47 and 70.54 , respectively. The minimum and maximum scores for MCS were 23.48 and 71.64, respectively. Out of 8 domains of the SF-12, the lowest score was for social functioning $(53.86 \pm 21.29)$ and highest score was for bodily pain $(73.31 \pm 23.1)$.

\section{Association between demographics characteristics, WAI and HRQoL scores}

The Table 2 shows the coefficient matrix of the measured variables. The mental component summary was significantly correlated with PCS $(r=0.271, \mathrm{p}=0.0001)$. The PCS and MCS were significantly correlated with the WAI $(r=0.422, p=0.0001$ and $r=0.369, p=0.0001$, respectively).

The Table 3 shows mean differences of the WAI based on characteristics of the workers. There was not any significant

Table 2. Correlation between quantitative demographics variables, scores of work ability index (WAI), and component summaries of health related quality of life

\begin{tabular}{lcccccc}
\hline & \multicolumn{5}{c}{ Pearson coefficient (r) } \\
\cline { 2 - 6 } \multicolumn{1}{c}{ Variable } & age & income & $\begin{array}{c}\text { work } \\
\text { experience }\end{array}$ & PCS & MCS & WAI \\
\hline Age & 1 & & & & & \\
Income & 0.024 & 1 & & & & \\
Work experience & $0.440^{* *}$ & -0.025 & 1 & & & \\
Physical component summary (PCS) & -0.060 & -0.004 & -0.090 & 1 & & \\
Mental component summary (MCS) & 0.035 & 0.052 & -0.072 & $0.271^{* *}$ & 1 \\
WAI & -0.029 & 0.042 & -0.057 & $0.422^{* *}$ & $0.369^{* *}$ & 1 \\
\hline
\end{tabular}

$* \mathrm{p}<0.05 ; * * \mathrm{p}<0.01$. 
Table 3. Work ability index (WAI) based on demographic variables

\begin{tabular}{lcc}
\hline \multicolumn{1}{c}{ Variable } & $\begin{array}{c}\text { WAI } \\
(\mathrm{M} \pm \mathrm{SD})\end{array}$ & $\mathrm{p}$ \\
\hline $\begin{array}{l}\text { Marital status } \\
\text { single }\end{array}$ & $35.68 \pm 5.30$ & \\
married & $34.73 \pm 5.67$ & \\
$\quad$ divorced & $27.12 \pm 2.85$ & \\
$\quad$ widow & $29.00 \pm 5.65$ & \\
Education & & 0.002 \\
$\quad$ high school graduated & $34.39 \pm 5.47$ & \\
$\quad$ university education & $36.47 \pm 5.55$ & \\
Shift of work & & 0.039 \\
$\quad$ non-shift work & $35.31 \pm 5.40$ & \\
shift work & $33.60 \pm 6.13$ & \\
Age & & 0.687 \\
$\quad<40$ year & $32.47 \pm 5.19$ & \\
$\quad \geq 40$ year & $31.42 \pm 4.80$ & \\
\hline
\end{tabular}

Abbreviations as in Table 1.

difference in the WAI across marital status of single and married (35.68 \pm 5.3 vs. $34.73 \pm 5.67, p=0.16)$. Mean score of the WAI was different based on educational level and time characteristic of working (shift work versus non-shift work) significantly ( $p=0.002$ and $p=0.039$, respectively). We compared the mean of the WAI across MCS and PCS subgroups. The WAI was higher for the group with better PCS $(37.14 \pm 5.45$ vs. $32.35 \pm 4.46, \mathrm{p}=0.0001)$. The WAI was also higher for women with better MCS as compared to women in the comparison group $(36.93 \pm 5.69$ vs. $33.14 \pm 4.75, \mathrm{p}=0.0001$ ).

The results of the multivariate linear regression analysis are shown in the Table 4. Variables such as educational level, shift of work, PCS and MCS were put into the model as covariates. It is shown that PCS $(\beta=0.23, p<0.0001)$ and MCS $(\beta=0.151, p=0.0001)$ have a positive significant association with the WAI after adjustment too. Finally, it is shown that $26.4 \%\left(\mathrm{r}^{2}=0.26\right)$ of variance of the work ability index could be predicted in this model.

\section{DISCUSSION}

The aim of this study has been to determine the association between the HRQoL, demographic characteristics and work ability of female workers. The mean of the WAI for female workers is about 35.02, which is considered moderate (28-36) according to the scale of the FIOH. The study of Eyvazlou et al. [19] on the workers of the automotive industry in Iran reported a good WAI (37.6). Considering higher mean age of workers in their study (35 years old vs. 27.6 years in our study), lower work ability in this study may be due to the difference in work conditions, workplace, and maybe life style [19]. In this study, $8.8 \%$ and $62.1 \%$ of women had poor and moderate work abilities, respectively. The study done by FIOH reported about

Table 4. Results of the multiple linear regression analysis for the work ability index (WAI) as a dependent factor

\begin{tabular}{|c|c|c|c|c|c|}
\hline \multirow{2}{*}{ Individual characteristic } & \multicolumn{2}{|c|}{$\beta$ coefficient } & \multirow{2}{*}{$\mathrm{p}$} & \multicolumn{2}{|c|}{$95 \% \mathrm{CI}$ for $\mathrm{B}$} \\
\hline & $\beta$ & SE & & lower bound & upper bound \\
\hline Constant & 16.69 & 2.09 & 0.0001 & 12.57 & 20.80 \\
\hline Low education ${ }^{1}$ & -0.89 & 0.59 & 0.1360 & -2.06 & 0.28 \\
\hline Shift work ${ }^{2}$ & -0.92 & 0.74 & 0.2140 & -2.38 & 0.53 \\
\hline Physical component summary (PCS) & 0.23 & 0.03 & 0.0001 & 0.16 & 0.29 \\
\hline Mental component summary (MCS) & 0.15 & 0.03 & 0.0001 & 0.08 & 0.21 \\
\hline
\end{tabular}

${ }^{1,2}$ References groups were high educational level and non-shift work, respectively.

$\mathrm{SE}$ - standard error; CI - confidence interval. 
$15 \%$ of poor and moderate work abilities for the moderate size industrial centers [20]. One probable explanation for this difference could be unfavorable work health conditions of the workers. Although, the main reasons should be assessed by future studies. Also, in the study on male workers in Finland done by Sörensen et al., most workers were reported to have average to good work abilities, which is almost consistent with the results of this study [12]. We found a positive association between the physical and mental component summaries of the HRQoL and WAI ( $p=0.0001, r=0.42, r=0.36$, respectively). These findings are compatible with results of the study done by Abdolalizadeh et al. [16] among nurses and healthcare workers. They showed a significant association between all domains of the HRQoL and work ability of individuals [16]. Also, in a study done by van den Berg et al. there was a positive association between the WAI and the physical and mental components of the HRQoL [21]. Therefore, considering and improving the factors associated with work ability of workers may improve their QOL too. Also, workers with better QOL could have a higher work ability. Higher work ability makes a good sense and could prevent early retirement in workers.

We found a weak and inverse association between the age of female workers and their work ability. Women older than 40 years of age had the lower WAI as compared to the younger group. This finding is consistent with results of the study on workers of the refinery done by Safari et al. [22]. The role of age as a natural factor in reducing the functional capacities is undeniable. Also, the majority of the previous studies have concluded that the work ability of the individuals older than 40 years of age, tend to decrease because of the decline in the aerobic capacity [19]. It has been reported that the functional capacities of the workers, especially physical abilities, tend to be weaker after reaching 30 years of age. If job demands aren't adjusted based on the biological changes, workers' capabilities will reach critical value in 15-20 years later (45-50 years) [19].
Low income job is one of the problems of the employed women in Iran and all over the world. Women have lower income than men in the same job. The severe poverty level is 5750000 Rials, according to the cut point released by the Committee of Tehran [23] in February of 2012. Therefore, about $50 \%$ of the studied female workers had an income below declared severe poverty. We showed a weak and positive correlation between income and work ability of women, although it was not significant.

We found a significant association between education and work ability of studied women. Women in the educational group of high school graduated reported their work ability lower than those with higher education $(p=0.002)$. The same results have been shown in the study of Eyvazlou et al. too [19]. In addition, a study done by Knezevic et al. has shown that subjects with lower education have worse work ability than those with higher education [24]. This finding could be explained by the observation that individuals with higher education have a better occupational, economical, and social characteristics in the majority of societies. These factors are determinants of work ability. The better condition of these characteristics could decrease the work-related risk factors and result in higher work ability [19].

In this study, work ability of non-shift work women was also better than for the shift-work group. In a study done by Habibi et al. [25] shift-work nurses had the lowest work ability. They reported shift work as one of the effective factors on the physical health of the workers [25]. Disturbances in the circadian cycle and sleep disorders as a consequence of shift work could be one explanation for this finding. Instability in shift work has more effect on women with additional responsibility for children and home. The WAI of single workers was a little higher than for married ones. Also, widowed and divorced women had a significantly lower work ability than single and married ones. These outcomes support the results of the study done by Habibi et al., in which the work ability for single nurses was significantly higher than for the married ones [25]. 
There was a reverse and weak association between the work experience and work ability of the workers. This result is supported by another study done by Somunen et al. too $[19,26]$.

The adjusted association of the WAI with PCS and MCS of health related quality of life is shown in the regression analysis. This indicates that the other variables do not have a confounding role in the association between these variables. Using the regression model, we could show that $13.7 \%$ and $17.8 \%$ of the variation in the WAI is determined by the MCS and PCS of health related quality of life respectively.

One of the important strong points of this study is doing survey on female workers. Performing studies on women especially female workers, and using such findings could improve their health and is an important issue in women's health. The other point is assessing the HRQoL, demographic characteristics and work ability concurrently in 1 survey. Small sample size and restricting the field of study to a specific industry could decrease the generalizability of the results and may be considered as limitations. Cross-sectional design is also another limitation to address the cause and effect associations. Self-reporting data should also be considered as another limitation of this study that could effect on reliability of findings.

\section{CONCLUSIONS}

As a conclusion, findings of this study indicate that work ability in female workers is not satisfactory. Therefore, periodic examinations and annual screening of these workers by means of the WAI is recommended. Physical and mental components of the HRQol were the most important factors associated with work ability of female workers.

\section{REFERENCES}

1. Messing K. One-eyed science: Occupational health and women workers. Philadelphia (PA): Temple University Press; 1998.
2. Messing K, Stellman JM. Sex, gender and health: The importance of considering mechanism. Environ Res. 2006; 101:149-62, http://dx.doi.org/10.1016/j.envres.2005.03.015.

3 . Women in labour markets. Measuring progress and identifying challenges. Geneva: International Labour Office; 2010.

4. Hausmann R, Tyson LD, Zahidi S. The global gender gap report. Geneva: World Economic Forum; 2008.

5. Punnett L, Herbert R. Work-related musculoskeletal disorders: Is there a gender differential, and if so, what does it mean? In: Goldman M, Hatch MC, editors. Women and health. New York: Academic Press; 2000. p. 474-92, http:// dx.doi.org/10.1016/B978-012288145-9/50044-9.

6. Vaillant N, Wolff F-C. [Stress, anxiety and depression at work. Are there differences between businesses?]. Nantes: Laboratoire d'Economie et de Management de Nantes-Atlantique; 2010. French.

7. Schonfeld I. An updated look at depressive symptoms and job satisfaction in first-year women teachers. J Occup Organ Psychol. 2000;73:363-71, http://dx.doi. org/10.1348/096317900167074.

8. Sanne B, Mykletun A, Dahl AA, Moen BE, Tell GS. Occupational differences in levels of anxiety and depression: The Hordaland health study. J Occup Environ Med. 2003;45: 628-38, http://dx.doi.org/10.1097/01.jom.0000069239.06498.2f.

9. Gallo LC, Boagart LM, Vranceanu AM, Walt LC. Job characteristics, occupational status, and ambulatory cardiovascular activity in women. Ann Behav Med. 2004;28:62-73, http://dx.doi.org/10.1207/s15324796abm2801_8.

10. The World Health Organization Quality of Life Assessment (WHOQOL): Position paper from the World Health Organization. Soc Sci Med. 1995;41:1403-9, http://dx.doi. org/10.1016/0277-9536(95)00112-K.

11. Ilmarinen J, Rantanen J. Promotion of work ability during ageing. Am J Ind Med. 1999;1(Suppl):21-3, http://dx.doi. org/10.1002/\%28SICI\%291097-0274\%28199909\%2936: 1+\%3C21::AID-AJIM8\%3E3.0.CO;2-S.

12. Sörensen LE, Pekkonen MM, Männikkö KH, Louhevaara VA, Smolander J, Alén MJ. Associations between 
work ability, health-related quality of life, physical activity and fitness among middle-aged men. Appl Ergon. 2008;39 (6):786-91, http://dx.doi.org/10.1016/j.apergo.2007.11.001.

13. Milosevic M, Golubic R, Knezevic B, Golubic K, Bubas M, Mustajbegovic J. Work ability as a major determinant of clinical nurses' quality of life. J Clin Nurs. 2011;20:2932-8, http://dx.doi.org/10.1111/j.1365-2702.2011.03703.x.

14. Ilmarinen J. Work ability - A comprehensive concept for occupational health research and prevention. Scand J Work Environ Health. 2009;35(1):1-5, http://dx.doi.org/10.5271/ sjweh.1304.

15. El Fassi M, Bocquet V, Majery N, Lair ML, Couffignal S, Mairiaux P. Work ability assessment in a worker population: Comparison and determinants of Work Ability Index and Work Ability Score. BMC Public Health. 2013;13(1):305, http://dx.doi.org/10.1186/1471-2458-13-305.

16. Abdolalizadeh M, Arastoo AA, Ghsemzadeh R, Montazeri A, Ahmadi K, Azizi A. The psychometric properties of an Iranian translation of the Work Ability Index (WAI) questionnaire. J Occup Rehabil. 2012 Sep;22(3):401-8, http:// dx.doi.org/10.1007/s10926-012-9355-3.

17. Rohani K, Abedi H, Langius A. The Iranian SF-12 Health Survey Version 2 (SF-12v2): Factorial and convergent validity, internal consistency and test-retest in a healthy sample. Iranian Rehabil J. 2010;8(12):6-14.

18. Montazeri A, Vahdaninia M, Mousavi SJ, Asadi-Lari M, Omidvari S, Tavousi M. The 12-item medical outcomes study short form health survey version 2.0 (SF-12v2): A population-based validation study from Tehran, Iran. Health Qual Life Outcomes. 2011;9:12, http://dx.doi.org/10.1186/1477-7525-9-12.

19. Eyvazlou M, Mazloumi A, Farshad A, Hoseini F. [Analytical evaluation of work ability index and its determining factors among workers of a car manufacturing industry]. Iran Occup Health. 2012;9(2):41-9. Persian.
20. Gould R, Ilmarinen J, Järvisalo J, Koskinen S, editors. Dimensions of work ability: Results of the Health 2000 survey. Helsinki: Finnish Center for Pensions, The Social Insurance Institution, National Public Health Institute, Finnish Institute of Occupational Health; 2008.

21. Van den Berg TI, Alavinia SM, Bredt FJ, Lindeboom D, Elders LA, Burdorf A. The influence of psychosocial factors at work and life style on health and work ability among professional workers. Int Arch Occup Environ Health. 2008;81(8):1029-36, http://dx.doi.org/10.1007/s0042 0-007-0296-7.

22. Safari SH, Habibi E, Dehghan H, Mahaki B, Hasan Zadeh A. [Job stress, employee education and ability to work in a refinery]. Occup Med Q J. 2013;5(3):1-10. Persian.

23. Avazi AA. Remuneration Committee of Tehran announced [Internet]. [Extreme poverty line, 5 million and seven hundered and fifty four thousand Rials] [cited 2012 March 5]. Available from: http://www.tabnak.ir/fa. Persian.

24. Knezevic B, Milosevic M, Golubic R, Belosevic L, Russo A, Mustajbegovic J. Work-related stress and work ability among Croatian university hospital midwives. Midwifery. 2011;27(2):146-53, http://dx.doi.org/10.1016/j.midw. 2009.04.002.

25. Habibi E, Dehghan H, Zeinodini M, Yousefi H, Hasanzadeh A. A study on Work Ability Index and Physical Work Capacity on the base of fax equation $\mathrm{VO}_{2}$ max in male nursing hospital staff in Isfahan, Iran. Int J Prev Med. 2012;3(11):776-82.

26. Sormunen E, Remes J, Hassi J. Factors associated with self-estimated work ability and musculoskeletal symptoms among male and female workers in cooled food-processing facilities. Ind Health. 2009;47:271-82, http://dx.doi. org/10.2486/indhealth.47.271.

This work is available in Open Access model and licensed under a Creative Commons Attribution-NonCommercial 3.0 Poland License - http://creativecommons.org/ licenses/by-nc/3.0/pl/deed.en. 